Derecho y Realidad

Núm. 22 • II semestre de 2013

Facultad de Derecho y Ciencias Sociales, UPTC

ISSN: 1692-3936

\title{
Bases constitucionales del sistema penal con tendencia acusatoria en un Estado social de derecho
}

\author{
Constitutional basis of the adversarial criminal justice \\ system in a social State of law
}

\author{
Cándida Rosa Araque de Navas*
}

\section{Resumen}

Este escenario es propicio para plantear algunos aspectos relacionados con la constitucionalización del derecho penal como expresión categórica de la vigencia de un auténtico Estado democrático de derecho centrado en la dignidad humana, con la consecuente humanización de la administración de justicia.

La Constitución de 1991 debe ser aplicada preferentemente en la actividad judicial. Lo cual implica que este catálogo normativo pasó de ser fuente formal a material del derecho, es decir, que las decisiones que se adopten en cualquier clase de juicio o procedimiento, deben tener en cuenta la Constitución -entiéndase integrada por el denominado bloque de constitucionalidad-, por cuanto así lo estatuye el artículo 4 superior: "La Constitución es norma de normas y prevalece sobre cualquier otra disposición que le sea contraria”.

Es precisamente esta situación la que originó una nueva lectura constitucional del proceso penal: derechos y garantías al cenit del principio acusatorio y el derecho internacional de los derechos humanos.

\footnotetext{
Magistrada Sala Penal Tribunal Superior, Distrito Judicial Tunja, Boyacá.
} 
Derecho y Realidad

\title{
Palabras clave
}

derecho penal, Constitución, sistema penal, principio acusatorio, Estado de derecho, sistema acusatorio.

\begin{abstract}
This scenario is suitable to consider some aspects related to the constitutionalization of criminal law as a categorical expression of a genuine democratic State of law focused on human dignity, with the subsequent humanization of justice administration.

The Constitution of 1991 should be applied preferably in judicial activity. It implies that this norm went from being formal to material source of law, i.e., that decisions to be taken in any kind of judgment or procedures should consider the Constitution-understood composed of the so-called Constitutional Bloc-, because so ordains its article 4: "The Constitution is the supreme law and prevails over any other provisions contrary to it".

It is precisely this situation that led to a new constitutional criminal reading: rights and guarantees on top of adversarial principle and international law of human rights.
\end{abstract}

\section{Key words}

criminal law, Constitution, criminal system, adversarial principle, State of law, adversarial system. 


\section{Introducción}

El cauce esencial para garantizar la efectividad de la seguridad jurídica es el "proceso justo" que respete los derechos constitucionales, por eso comenzaremos por tratar el principio fundamental de la seguridad jurídica, que no solamente atañe al proceso penal reglado en la Ley 906 de 2004, sino a todas las áreas del derecho como elemento integrador de este, y factor imprescindible en todo Estado de derecho, ante su inevitable necesidad y su carácter consustancial al derecho, que junto a estas premisas permite afirmar su legitimidad.

La seguridad jurídica conduce a la afirmación de la certeza del derecho, y debe ser enfocada en un doble plano: por una parte, es necesario que el ciudadano tenga confianza, que se sienta seguro; el Estado debe conseguir crear y mantener un sistema que proporcione a los ciudadanos un sentimiento de confianza. Este sentimiento es el presupuesto subjetivo de la seguridad jurídica y que para diferenciarse del aspecto objetivo, recibe denominación de seguridad jurídica en estricto sentido. Frente a esta designación, es utilizada la de "certeza jurídica" para referirse al otro plano de la cuestión, el objetivo, aun cuando suelen emplearse los dos términos como sinónimos.

Esa confianza del ciudadano solo puede lograrse mediante un sistema normativo que realmente opere con los medios adecuados para asegurar dicho sentimiento, ese entramado normativo proporcionará la visión objetiva de la seguridad jurídica.

La doctrina y jurisprudencia internacional y nacional, sostienen que "La seguridad jurídica demuestra la certeza y la permanencia de las situaciones jurídicas, vale decir, de las que están regladas por el sistema del Derecho".

"La seguridad jurídica se evidencia a través de ciertas cualidades o características que deben tener el sistema político y jurídico de un Estado. Así, la igualdad ante la Ley, sin distinciones de condición; su formulación clara, precisa y emanada de los órganos constitucionales competentes; la publicidad y el consiguiente conocimiento que de ella tengan quienes a su imperio estén sujetos; la irretroactividad de sus mandatos y, en fin, un cierto grado de permanencia y estabilidad que evita la volubilidad normativa y permite comprobar su pertinencia respecto de las relaciones sociales que regula". La estabilidad de las decisiones judiciales, en la medida que constituyen un presupuesto ineludible de la seguridad jurídica es exigencia de orden público, siendo el respeto por la cosa juzgada uno de los pilares fundamentales sobre los que se asienta nuestro sistema constitucional, está vinculada a la seguridad de las decisiones y es uno de los presupuestos del ordenamiento social cuya ausencia o debilitamiento pondría en crisis la íntegra juridicidad del sistema. El Estado, como ente del poder público de las relaciones en sociedad, no sólo establece los 
lineamientos y normas a seguir, sino que en un sentido más amplio tiene la obligación de establecer "seguridad jurídica" al ejercer su "poder" político, jurídico y legislativo.

La seguridad jurídica es la garantía dada al individuo por el Estado, de que su persona, sus bienes y sus derechos no serán violentados, o que si esto llegara a producirse, le serán asegurados por la sociedad, su protección y reparación.

En síntesis, la seguridad jurídica es la certeza que tiene el individuo de que su situación jurídica no será modificada sino por procedimientos regulares y conductos establecidos previamente. En la mayoría de los ordenamientos jurídicos positivos, existen normas destinadas a realizar este principio.

El derecho es concebido por el hombre en sociedad, por la necesidad urgente de seguridad y certeza, es decir, que su creación va encaminada a establecer el orden en la vida social. El derecho es, ante todo, seguridad. El Estado contemporáneo es siempre, o por lo menos debe ser un Estado de derecho. Todas las instituciones del Estado moderno parten de la idea de que el Estado es de derecho, así lo dice la trayectoria en la historia de los Estados modernos con la expresión de garantizar los derechos subjetivos e individuales

El derecho debe estar sustentado por valores superiores, como la justicia, y solo así encuentra justificación su existencia, porque nace de más necesidades que se dan perentoriamente en la vida social: la urgencia de certeza y seguridad y, al mismo tiempo, la necesidad de cambio progresivo; la urgencia de resolver los conflictos de intereses, y la necesidad de organizar, legitimar y restringir el poder político.

Las constituciones actuales son la respuesta legítima y estatutaria a los cambiantes intereses e ideales de un pueblo. Por ello, a fin de mantener un Estado de derecho en donde las leyes prevalezcan sobre los hombres, es que exista una cultura del derecho, que permita que el ciudadano, el pueblo en general, tenga los conocimientos básicos de los derechos que les asisten y los deberes consecuentes.

La confianza cierta en el orden jurídico, del que se espera tutela y efectiva vigencia de las garantías a los derechos de la persona humana, es, pues, también una faceta insoslayable de la seguridad. Íntimamente relacionada con ella está la certidumbre de la legitimidad del propio obrar conformado a la ley, certidumbre a la que coadyuva decididamente la estabilidad del sistema jurídico y judicial, dada por la razonable predictibilidad de las soluciones jurisdiccionales. Nada atenta más contra un sistema judiciario, y el valor Justicia que éste realiza y representa, que la volubilidad de las decisiones, síntoma inconfundible de un irresponsable ejercicio del poder que en 
aquél se deposita. El individuo que carece de un mínimo grado de certeza en cuanto al presente y al futuro de sus relaciones jurídicas y no jurídicas, es un ser expuesto, indefenso, a quien se le niega lo esencial de lo humano; el uso de sus facultades racionales para entender, planificar y prever su destino y evolucionar según sus propios términos.

La seguridad apela igualmente a un sentido de estabilidad del derecho, vale decir, la vigencia de un sistema normativo que no está sujeto a ocurrencias circunstanciales, sino que se afirma en la seria garantía de modificaciones que, de ser necesarias, vienen sugeridas por la experiencia y siempre por vía de mecanismos constitucionales incuestionables.

No puede haber justicia donde se vulneren principios vertebrales de la seguridad jurídica, como recalca con estos acertados términos, Gustavo Radbruch: "Un Derecho incierto es al mismo tiempo injusto, porque no puede asegurar para el porvenir un trato igual ante hechos iguales".

La Corte Constitucional de Colombia y la Corte Suprema de Justicia, desde 1991 se han pronunciado en numerosos fallos sobre la importancia de la seguridad, como un factor que integra el concepto mismo de justicia.

El verdadero sentido de la seguridad jurídica, afirma el tratadista Juan M. Farina en su obra Justicia, Ficción y Realidad, radica en

otorgar a cada persona la garantía de que, llegado el caso, será juzgada con imparcialidad por jueces probos, de moral sin tacha, conocedores de la materia que tienen que resolver, dispuestos a indagar en profundidad la verdad de los hechos y de las concretas circunstancias del caso, buscar el derecho aplicable y poder así resolver con prudencia y equidad", lo que ratifica diciendo: "Sin jueces virtuosos, dignos de respeto por su conducta recta y su decidida voluntad de hacer justicia en el sentido moral y de equidad que ello implica, la seguridad jurídica se convierte en algo aleatorio, diríamos inexistente, pues seguridad jurídica en el proceso judicial implica saber que nadie será sorprendido con medidas solapadas dictadas en violación de la normativa vigente; que cuando una norma es claramente aplicable al caso, no se recurra a argumentos para no aplicarla con equidad; cuando no es claramente aplicable, se busque la interpretación que sea compatible con la moral, la prudencia y la; que no se hagan trampas en el proceso; que no se violen las garantías esenciales que consagra la Constitución Nacional; que no se violen el trato igualitario y respetuoso que merecen ambas partes; que no se recurra a presunciones arbitrarias carentes de fundamentos serios y ciertos; que no se haga del proceso judicial una ficción donde, de antemano, todo está resuelto en favor de una de 
las partes; que no se convierta el Juez en un espectador de un certamen de habilidades procesales.

La Constitución colombiana consagra el principio de seguridad jurídica en el artículo 2 y el preámbulo al estatuir que el Estado colombiano asegura a sus habitantes la vida, la convivencia, el trabajo, la justicia, la igualdad, el conocimiento, la libertad y la paz, dentro de un marco jurídico, democrático y participativo que garantice un orden político, económico y social justo, y comprometido a impulsar la integración de la comunidad latinoamericana. Entre los fines primordiales del Estado se integran garantizar la efectividad de los principios, derechos y deberes consagrados en la constitución, y la vigencia de un orden justo.

Cuando impera la ley para todos, ninguna persona puede sentir el temor a arbitrariedades que son incompatibles con un verdadero Estado de derecho. Se trabaja al servicio de altos y fundamentales principios de derecho, cuando se actúa en bien de la seguridad jurídica que tiene uno de sus pilares en la imparcialidad de los jueces. La objetividad de las decisiones y su conformidad con el orden normativo legal y jurisprudencial dependen en gran medida de ese valor. La equidistancia del juzgador, tanto en lo legal como en lo moral, asegura al justiciable la satisfacción de este principio y dota de confiabilidad al sistema.

La seguridad jurídica influye en el crecimiento económico, porque la decisión de sus actores depende de sus expectativas respecto al futuro, en primer lugar, y de las expectativas de los otros, en segundo lugar. Los problemas que surgen de la incertidumbre, acciones no cooperativas o inconsistencia temporal, se resuelven dentro de la lógica de las reglas.

El concepto de seguridad implica también el reconocimiento irrestricto de la persona en cuanto sujeto de derechos, el afianzamiento de la soberanía como fuente del orden instituido, la supremacía de la Carta Magna, la división de los poderes constituidos y su recíproco equilibrio, la independencia de la judicatura, la responsabilidad de los actos de la administración y el control de éstos a través de mecanismos eficaces.

La seguridad jurídica zozobra cuando se encuentra con una sociedad transgresora que cumple las reglas según su humor. La discrecionalidad es fuente de graves riesgos para el imperio del derecho, provocando el desencanto y el desconcierto del pueblo.

Se puede aseverar sin lugar a vacilaciones que la seguridad jurídica es fuente primerísima de sosiego para el cuerpo social. Genera en la psiquis colectiva las condiciones imprescindibles para el desenvolvimiento de los talentos y las facultades individuales $\mathrm{y}$, en este ítem, permite el desarrollo de los esfuerzos privados y 
públicos que estimulan el bienestar económico y suscita el clima propicio para las inversiones que proveen las tan necesarias fuentes de trabajo. Así se impone concretar la justicia social empeñada en multiplicar las ocupaciones, basadas en el respeto a la dignidad humana y al derecho intangible a trabajar para crear bienes espirituales, morales y materiales que conviertan en realidad el legítimo anhelo de un desarrollo sin exclusión social con amplias oportunidades para todos a fin de alcanzar la plenitud humana.

Esa seguridad jurídica, se reitera, implica la vigencia real de la supremacía de la Constitución con plenas garantías para el hombre y la sociedad, que constituye principio fundamental de todo Estado de derecho.

De ahí, que en el ámbito de aplicación de las normas, la seguridad jurídica exige una cierta estabilidad que se conforma mediante la uniformidad de la jurisprudencia, sin perjuicio del carácter evolutivo del derecho, puesto que, acorde con la realidad social, deben dictarse unas orientaciones claras y precisas que marquen perfectamente la línea de aplicación de las normas jurídicas que sean más adecuadas para la consecución de la justicia desde una óptica de legalidad formal y material que preserve el espíritu de confianza que todo ciudadano debe tener en un Estado social y democrático de derecho. Una jurisprudencia carente de uniformidad o inalterable y no evolutiva, son claras manifestaciones de inseguridad jurídica, y por tanto, contraria al Estado de derecho. Es obvio que la jurisprudencia es, y debe ser, mudable, pero han de ajustarse a las exigencias de la seguridad jurídica, de donde se deriva la necesidad de una cierta estabilidad.

Otro factor que incide de manera decisiva sobre la seguridad jurídica, se encuentra constituido por las personas que han de aplicar las normas en los litigios que se susciten. El nombramiento de personas inadecuadas o insuficientemente formadas para los puestos judiciales implica una importante puesta en peligro de la seguridad jurídica, y que se puede decir de funcionarios con pérdida de valores, que utilicen la justicia en función de una serie de intereses ajenos a ésta.

En suma, en un Estado de derecho, republicano y democrático, debe primar por sobre todo el imperio de la ley, creada por la vías constitucionales y con miras al bien común; nunca el arbitrio discrecional de un gobernante o la anarquía irresponsable de los actores sociales. En esto estriba la diferencia entre un Estado de derecho y la tiranía, o entre un Estado de derecho y el desgobierno.

Exaltando el concepto y la significación de la seguridad jurídica, se trabaja también para mantener sólidos los cimientos de la democracia. La convivencia social encuentra su ratio en la seguridad jurídica, cuya efectiva consecución justifica la nación políticamente organizada. 
Planteado lo anterior, se pueden desarrollar en toda su dimensión los demás fundamentos, bases o pilares de orden supralegal que caracterizan la arquitectura del Sistema Penal con Tendencia Acusatoria, que se clasifican en tres grandes categorías:

1. Principios relacionados con la organización del sistema penal del que hacen parte el juez, predeterminado por la ley, la independencia e imparcialidad, como el denominado "plazo razonable".

2. Principios relacionados con el procedimiento: legalidad, oficialidad y acusatorio.

3. Principios relacionados con las pruebas: inmediación, contradicción.

4. Principios relacionados con la forma: publicidad y oralidad.

Analizados uno a uno los principios del SPA insertos en los cuatro grandes bloques enunciados, tenemos:

\section{Principio de legalidad}

La Constitución en el artículo 29 consagra el principio de legalidad en su acepción tradicional de prohibición de retroactividad y consecuentemente juzgamiento conforme a las leyes preexistentes. Enunciado al que se añade la formulación del artículo 250, que desarrolla el postulado radicando en cabeza de la Fiscalía General de la Nación las labores de persecución penal.

El principio de legalidad también tiene asiento en la normatividad Internacional en los artsículos 8.1 y 8.2 de la Convención Americana de Derechos Humanos -CADH-.

El principio de legalidad en la Ley 906 de 2004 se ha flexibilizado con el fin de dar cabida a los preacuerdos y negociaciones entre Fiscalía e implicados, sin que en manera alguna se omita en absoluto o se anule.

De otra parte, se incluye la aplicación del principio de oportunidad, que se suele mostrar como opuesto al de legalidad, cuando lo cierto es que tal enfrentamiento es relativo y en ciertos aspectos ciertamente aparente. Basta decir que parece que la legalidad únicamente se encuentra en el principio de legalidad y, por consiguiente, que el principio de oportunidad es un principio al margen de la legalidad. Evidentemente, partiendo de esta premisa, habría que afirmar decididamente que el principio de oportunidad es inadmisible. No obstante, tal premisa no es correcta, pues, cuando se habla de principio de oportunidad se está refiriendo a un principio 
que también se mueve en el ámbito de la legalidad -con mayor razón cuando no es discrecional sino reglado en nuestro país-. En el momento que el principio de oportunidad se enmarca legalmente, el que actúa conforme al principio de oportunidad lo hace en el campo de la legalidad, esto es, la oportunidad es legalidad.

Los principios de legalidad y oportunidad tienen que ser referidos al ejercicio de la acción penal. Con el principio de legalidad quiere indicarse que en el sistema regido por el mismo, los órganos de persecución en todo caso, esto es, en cuanto que un hecho revista los caracteres de delito, vienen obligados a ejercitar la acción penal (tanto para la investigación como para obtener la realización del ius puniendi), sin que pueda atenderse a ninguna otra consideración. Por el contrario, con el principio de oportunidad, el sistema de enjuiciamiento permite tomar en consideración otras circunstancias y en función de ellas decidir si es adecuada o no la persecución del hecho.

\section{Principio de investigación oficial}

La persecución de los hechos punibles corresponde al Estado, rige el principio de oficialidad, aun cuando las leyes instrumentales puedan exigir en algunos casos la iniciativa del ofendido a título de denunciante o querellante, sin que el órgano estatal competente pierda su titularidad de realizador de la investigación

La actividad de la Fiscalía en el principio de instrucción, como también se llama la oficiosidad, no es absoluta sino limitada por la misma Constitución, con una serie de exigencias que impone el artículo 250 de la Carta y las condiciones de aportación probatoria contenidas en el artículo 29 ibídem. La Fiscalía, como parte de la administración pública, no puede actuar parcialmente, pues está sujeta, como el juez, al principio de legalidad.

Las limitaciones expresas al principio de investigación, y por ende a la averiguación de la verdad material, que se pueden extraer del texto constitucional, configuran el catálogo de garantías para las personas que son objeto de persecución penal.

\section{Principio acusatorio}

Es el principio de mayor importancia en el SPA, con acercamiento a la estructura penal continental europea.

Tiene las siguientes características básicas y esenciales que enmarcan la cuestión: (i) separación entre el órgano investigados/acusador y el juzgador; (ii) sin acusación no hay juicio o no hay condena, el principio acusatorio impone que si no hay acusación no puede abrir un juicio oral contra alguna persona. En el caso que 
hubiere acusación y se hubiere seguido un juicio oral, pero la parte acusadora retira la acusación, necesariamente el juzgado no puede condenar y debe dictar sentencia absolutoria; (iii) la condena no puede ir más allá de la acusación, congruencia entre acusación y sentencia por su exigencia estricta de correlación, por estrecha vinculación con la acusación tanto fáctica como jurídica; (iv) la proporción y producción de pruebas queda en manos de las partes, exclusión decreto pruebas de oficio; y, (v) prohibición de la reformatio in pejus, valga decir, reiteración y formulación de la acusación ante el juez ad quem.

\section{Principio del juez legal}

Este principio es producto de la separación de funciones en el proceso o más exactamente de la desconcentración de funciones, pues de conformidad con el principio acusatorio, el proceso parte de la investigación adelantada y la acusación formulada por un funcionario del Estado, titular de la acción penal, que en un juicio público se enfrenta a un defensor encomendado de preservar la presunción de inocencia del acusado o de garantizar la legalidad de la pena, ante un juez delegado de decidir cuál de los adversarios logró, con fundamento en las pruebas y sus argumentos, demostrar la validez fáctica y jurídica de sus pretensiones.

Por ello, por el principio de la separación o desconcentración de funciones, propio del sistema acusatorio, el juez, si quiere conservar su imparcialidad, no puede intervenir en los actos de investigación ordenando pruebas de oficio, interrogando, salvo en ocasiones excepcionales, a los testigos o a los peritos, porque ello equivaldría a intervenir en la teoría del caso de uno de los adversarios que son los que saben, de acuerdo a sus pretensiones, cuales son las pruebas que convienen a sus intereses. Por ello la labor del juez se reduce a decidir si la razón está de lado de la fiscalía o de la defensa en cuanto a las circunstancias de tiempo, modo y lugar en que ocurrieron los hechos que dieron lugar a la acusación y a su calificación jurídica, sin que ello implique que no sea el director del proceso facultado para garantizar la igualdad de armas pero no para desequilibrar la balanza a favor de una de las partes.

Lo anterior con fundamento en lo dispuesto por el legislador en cumplimiento del Acto Legislativo 3 de 2002, donde optó por un sistema adversarial, modulado.

La imparcialidad del juez implica, por otro lado, un juez natural, independiente, autónomo y plenamente identificado por el acusado con lo que se garantiza que el juez encargado de dictar sentencia es el mismo que presidió la audiencia, que presenció el contradictorio, que estuvo durante el desarrollo del juicio oral, que no se ausentó durante su trámite y que, con apoyo en los principios de inmediación y concentración, tiene los elementos de juicio para valorar únicamente la prueba practicada frente a él y fallar con fundamento en dicha valoración. 
La imparcialidad que se predica del juez de conocimiento, tal como lo dispone el artículo $5^{\circ}$ del nuevo C.P.P., se hace extensiva al juez de control de garantías, porque como juez constitucional que es, encargado de velar por los derechos fundamentales de los intervinientes en el proceso, especialmente del imputado de indebidas e innecesarias intromisiones de la Fiscalía, debe tratar de conservar un equilibrio justo entre los intereses de la sociedad en la persecución del delito y los derechos del imputado en respeto a sus garantías. A fin de lograr esa imparcialidad y de que el juez de conocimiento no se contamine con los actos de investigación, es que el juez de garantías no puede, ulteriormente en el proceso, fungir como juez de conocimiento.

El legislador de 2004 consagró expresamente en el artículo 5º de la Ley 906 de 2004, el principio de imparcialidad, sin dejar de lado la dirección del proceso que debe ejercer el juez para la correcta operatividad del sistema.

\section{Principio de publicidad}

Característica esencial del sistema acusatorio es la publicidad que se opone a lo secreto, lo que implica que las actuaciones judiciales serán públicas tanto para las partes como terceros ajenos a ellas, salvo las disposiciones legales pues este principio no es absoluto, sino que admite ciertas excepciones, carácter de público porque ello "asegura el control, tanto externo como interno, de la actividad judicial. Conforme a ella los procedimientos, de formulación de hipótesis y tanto para las partes como para tercero ajenos a ellas, de determinación de responsabilidad penal tiene que producirse a la luz del sol, bajo el control de la opinión pública y, sobre todo del imputado y su defensor. Se trata seguramente del requisito más elemental y llamativo del proceso acusatorio..." (Corte Constitucional, sentencia C-836, 2001)

Este principio, que ha sostenido el alto Tribunal Constitucional en sentencia SC836 de 2001, se deriva del hecho cierto de que en un Estado de derecho, respetuoso de la legalidad y la igualdad, la sociedad tiene el derecho a saber cómo los jueces administran justicia, cómo restablecen, con sus decisiones, la confianza en el ordenamiento jurídico, cómo garantizan el respeto a los derechos fundamentales de los victimas y de los acusados, si sus decisiones son uniformes y consistentes, en fin cómo aseguran la convivencia pacífica y la paz social y si en tal cometido respetan los principios, valores y reglas que manda la Constitución.

La Corte Constitucional ha señalado que son varias las finalidades constitucionales que se escrutan:

i) Es una herramienta de control a la actividad judicial, ya que sirve de medio para el ejercicio de los derechos de contradicción e impugnación destinados a 
corregir las falencias en que incurre el juzgador. ii) Otorga a la sociedad en si misma considerada, un medio para preservar la transparencia y razonabilidad de las decisiones judiciales... iii) ... conduce al logro de la obediencia jurídica en un Estado democrático de derecho, ya que solo en la medida en que las personas tienen conocimiento de las actuaciones judiciales, esto es, del principio, regla o razón jurídica que constituye la base de una decisión judicial, las partes o los interesados podrán apelar a dicho fundamento para ajustar su conducta a las decisiones de los jueces...También la imperatividad y obligatoriedad de las sentencias judiciales suponen su publicidad, pues lógicamente aquello que es desconocido por las partes o terceros no puede ser objeto de imposición, so pena de alterar y desconocer los valores, reglas y principios de un Estado Social de Derecho y iv) finalmente se da certeza sobre el contenido y alcance de los derechos y obligaciones de las personas. Por consiguiente puede concluirse que el papel que cumple el principio de publicidad en un sistema democrático, es trascendental ya que gracias a él, es posible averiguar la imparcialidad, la moralidad y la veracidad de los procesos. (Sentencia C-641, 2001)

De conformidad, entonces, con el artículo 18 y el capítulo II del Título VI de la Ley 906 de 2004, desarrollo del artículo 228 de la Constitución Nacional, la “actuación procesal será pública. Tendrán acceso a ella, además de los intervinientes, los medios de comunicación y la comunidad en general”, lo que garantizará su transparencia.

\section{Principio de oralidad}

Es presupuesto del principio de publicidad, ligado con los de inmediación y concentración, e impone que las actuaciones procesales sean principalmente orales, sin perjuicio de su documentación escrita. La oralidad impone que la sentencia y las resoluciones judiciales solo pueden basarse en material presentado oralmente. La oralidad impide, por otro lado, que el juicio se adelante en etapas o fases que desdibujan, por el paso del tiempo, la desconcentración y la distracción, la verdad.

La oralidad es principio procesal que permite no solo la concentración del proceso sino que garantiza la inmediación del órgano de la prueba a lo largo del juicio, pues es el único mecanismo que genera un sistema dinámico de comunicación entre el juez, las partes y los medios de prueba, permitiendo, al mismo tiempo, construir, de modo controlado y eficaz, la verdad, con lo que se asegura la plena realización del contradictorio como producto de la interacción entre las partes, en un equilibrado y reglamentado juego de interrogatorios y contrainterrogatorios, cuya agilidad y fluidez no se puede alcanzar a través de la palabra escrita.

Conforme al artículo $9^{\circ}$ de la Ley 906 de 2004, inserto en el capítulo I del Título VI, "la actuación procesal será oral y en su realización se utilizaran los medios 
técnicos disponibles que permitan imprimirle mayor agilidad y fidelidad, sin perjuicio de conservar registro de lo acontecido", lo cual se dirige irrefutablemente a garantizar la inmediación y contradicción de la prueba, además de la concentración, publicidad y continuidad de un juicio pronto y cumplido.

Según el transcrito principio "fundamento de una sentencia solo puede ser aquello que fue expuesto oralmente. Todo lo que suceda en el proceso, por ej., el interrogatorio del acusado, la producción de la prueba, los alegatos, debe ser llevado a cabo oralmente (también la deliberación, la votación y el pronunciamiento de la sentencia) en contraposición con el principio escriturista quod non est in actis, non est in mundo, lo que no ha sido dicho no es tomado en cuenta, sino que es considerado como no sucedido o no existente" (Roxin, 2000, p. 115)

Este principio implica, entonces, i) La exclusión de las declaraciones y pericias escritas como fundamento de la sentencia, ii) El testimonio, el dictamen y los informes se rendirán de manera oral por los acusados, testigos, peritos e investigadores, iii) La admisión de la prueba anticipada y de referencia será excepcional ${ }^{1}$, iv) La exclusión de la prueba de referencia como soporte exclusivo de la sentencia ${ }^{2}$, v) la prohibición de alegatos escritos para fiscales, ministerio público y defensores, vi) las decisiones del juez se tomarán de manera oral en la audiencia pública, vii) las peticiones, alegatos y recursos deberán interponerse en la audiencia de manera oral y viii) los recursos se sustentarán en forma verbal frente a los jueces competentes.

Para el procesado implica: a) Que toda la prueba debe verterse y practicarse de manera oral, con lo que la asistencia de los peritos, testigos y demás intervinientes debe ser obligatoria; b) Que se permita que el juez reciba de manera directa y de viva voz la versión de los hechos que tienen los testigos, lo que a su vez permite poder determinar con más precisión la credibilidad, conocimiento, parcialidad y capacidad de recordación, entre otros, de los intervinientes en la práctica de las pruebas; c) Implica, como ya vimos la obligación de presencia, pero no sólo del procesado sino también del juez, quien debe estar atento a lo que suceda en la audiencia; d) Que todas las solicitudes se tramitarán previa audiencia de la otra parte; e) Constituye una garantía frente a las partes y frente a la sociedad que puede reconocer y advertir la respuesta del Estado frente al crimen, lo que facilita el aumento de la confianza en el sistema judicial ${ }^{3}$.

\footnotetext{
Ley 906 de 2004. Artículo 379 "(la) admisión de la prueba de referencia es excepcional".

2 Ley 906 de 2004. Artículo 381 "(la) sentencia condenatoria no podrá fundamentarse exclusivamente en prueba de referencia".

3 Defensoría del Pueblo, Unidad de Capacitación, "Axiología y Deontología del Proceso Penal, Antecedente Judicial", Programa de fortalecimiento y acceso a la justicia.
} 


\section{Principio de concentración}

Principio que se define como las posibilidad de ejecutar la máxima actividad del procedimiento en la fase 'principal o etapa oral. La concentración, celeridad y oralidad forman el trípode sobre el que descansa la ritualidad del procedimiento con principio acusatorio, y sus excepciones se refieren a aquellos casos en los que es permisible la interrupción de la fase procesal por imposibilidad que la prueba se practique en la sede del juicio.

En el principio de concentración o de unidad de acto toda la prueba debe realizarse concentradamente. Es un principio que no rige durante la investigación y que es de indiscutible vigencia en el juicio oral. Se trata de evitar que pueda juzgarse de forma inadecuada a una persona y para ello se impone la regla de que todo el juicio debe llevarse a cabo de forma unitaria; no obstante, esto no impide que puedan existir diversas sesiones del juicio oral, pero siempre y cuando que entre ellas no transcurra un excesivo espacio de tiempo.

La Ley 906 es clara al respecto, cuando estatuye en sus artículos 17 y 454 que durante la actuación procesal la práctica de pruebas y el debate deberá, realizarse de manera continúa. La audiencia del juicio oral deberá ser continua salvo que se trate de manifestaciones sobrevinientes y sin existir otra alternativa viable.

Este nuevo sistema se encuentra en plena construcción del sistema penal con tendencia acusatoria propia, desde el año 2005, lo que quiere decir que hoy se tienen académicamente formadas las primeras generaciones que van a dar ese cambio definitivo, pues se trata de un proceso de transformación y evolución mental y de cultura jurídica, que permite asegurar que en un futuro no muy lejano se implementen otros principios medulares del sistema, como sería el "principio del plazo razonable", que se deduce del artículo 6.1 de la Convención Europea de Derechos Humanos $\mathrm{CEDH}$, donde se establece que "toda persona tiene derecho a que su causa sea oída...dentro de un plazo razonable", y de forma similar, el artículo $14.3 \mathrm{c}$ ) del Pacto Internacional de Derechos Civiles y Políticos -PIDCP-, señala que "toda persona...tiene derecho... a ser juzgado sin dilaciones indebidas".

Se trata de un derecho de naturaleza prestacional que no puede relacionarse con el atasco y la congestión que puedan existir en los órganos jurisdiccionales o en alguno en concreto.

El juicio debe ser llevado a cabo dentro de un plazo razonable. Los criterios que se deben tener en cuenta para fijar el plazo razonable según la doctrina del Tribunal Europeo de Derechos Humanos, son: el tipo de proceso de que se trate, la 
complejidad del asunto, el comportamiento del requirente y, el comportamiento de las autoridades competentes.

El incumplimiento del término razonable por la existencia de dilaciones indebidas para evacuar el juicio, se debe declarar en la respectiva sentencia. Cuando no es posible remover los obstáculos, y concluir el procedimiento, porque la lesión ya se ha perpetrado, surge el problema de reparación, por el perjuicio causado a un derecho fundamental. Y si no es posible la reparación, incluso se ha intentado indultar por parte del Ejecutivo, en la declaración de la existencia de dilaciones indebidas en el procedimiento, $\mathrm{y}$, en su caso, se añadirá la solicitud de una indemnización. Que sería una forma extrema de responder a estos casos. Quedando en lo máximo suspendida la ejecución de la sentencia como lo ha interpretado el Tribunal Supremo de España en su Sala Penal, en las sentencias STS 934 de 1999 del 8 de junio, STS 742 del 22 de mayo de 2003, con la imposición de la doctrina de compensación.

\section{Lista de Referencias}

Convención Americana sobre Derechos Humanos, o "Pacto de San José”.

Convenio Europeo para la Protección de los Derechos Humanos y las Libertades Fundamentales.

Corte Constitucional. Sentencia T-465 de 1994 C-599/92, C-412/93, C-19/93, C-114/93, C-176/94, C-179/94, C-214/94, C-428/94, C-509/94, SU-44/ 95, C-37/96, C-218/96, C-339/96, C-427/96, C-431/96, C-432/96, C-491/ 96, C-597/96, C-609/96, SU-620/96, SU-624/96, C-657/96, C-690/96, C-40/97, C-198/97, C-239/97, C-346/97, C-475/97, C-510/97, C-540/97, C-5/98, C-56/98, C-145/98, C-184/98, SU-250/98, SU-429/98, C-573/98, C-133/99, C-369/99, C-836/01, C-641/01, C-416/02, C-591/05.

Corte Suprema de Justicia. Sentencia 24.468 de 30 de marzo 2006.

Declaración Americana de los Derechos y Deberes del Hombre.

Declaración de Derechos del Buen Pueblo de Virginia.

Declaración Universal de los Derechos Humanos.

Ferrajoli, L. (1995). Derecho y Razón. Madrid: Trotta. 
166

Derecho y Realidad

Estatuto de la Corte Penal Internacional.

Pacto Internacional de Derechos Civiles y Políticos.

Reglas de Mallorca.

Roxin, C. (2000). Derecho procesal penal. Buenos Aires: Editores del Puerto. 